\title{
Julia Hermann, Jeroen Hopster, Wouter Kalf and Michael Klenk: Philosophy in the Age of Science? Inquiries into Philosophical Progress, Method, and Societal Relevance. Rowman \& Littlefield, 2020.
}

\author{
Peter Königs ${ }^{1}$ \\ Accepted: 21 March 2021 / Published online: 8 April 2021 \\ (C) The Author(s) 2021
}

The edited volume Philosophy in the Age of Science?, a festschrift for Herman Philipse, revolves around three major topics: philosophical progress, philosophical method, and the societal relevance of philosophy. By exploring these three themes with a special focus on their relation to science, the thirteen articles collected in the volume, from both junior and senior philosophers, seek to achieve a better understanding of the place of philosophy in our scientific age. A major merit of the volume is that it provides perspectives from such diverse philosophical disciplines as ethics, philosophy of science, philosophy of religion, philosophy of language, metaphysics, and phenomenology. It thus offers a welcome breadth of perspective in a time of increasing specialization. Readers of this journal will be particularly interested in the ethical contributions, some of which will be briefly reviewed below.

In a chapter that elegantly connects all three overarching themes of this volume, Julia Hermann makes the case for giving context a more prominent role in ethical inquiry. She discusses contexualist perspectives on justice, privacy and risk, adding a twist by arguing that contextualist approaches are particularly well suited to bring about ethical progress and to render ethics relevant for society. Ethics that takes into account contextual concerns is better able to do justice to the dynamic nature of ethics and to provide concrete practical guidance.

Wouter Kalf outlines his own theory of conceptual engineering and explores how error theorists, who do not believe in the existence of moral facts, can engage in conceptual engineering for the purpose of philosophical progress. He suggests that the conceptual engineering efforts of error theorists should be guided by the aim of improving prudential wellbeing, a realm of normative discourse that is typically exempt from error-theoretic skepticism. Specifically, he suggests that the term 'morally good' should be engineered in such a way that it moralizes actions that concern non-human animals and the environment, arguing, perhaps surprisingly, that this will advance the prudential interests of those whose actions will be constrained by this re-engineering of 'morally good'.

Peter Königs

peter.koenigs@ rwth-aachen.de

1 Human Technology Center/Applied Ethics, RWTH Aachen University, Theaterstraße 14, 52062 Aachen, Germany 
Perhaps one of the highlights of the volume is Sophie-Grace Chappell's essay on the point and purpose of systematisation in ethics. Chappell argues that the importance of systematic reasoning in ethics has been grossly overstated, observing that champions of this approach have difficulty answering three important question: They struggle to offer a compelling account of what qualifies as philosophical success, dealing awkwardly with counterexamples and questions of ontological parsimony. They do not have a convincing answer to what (or whom) moral theory is about, often relying on an overly generic account of human psychology. And it is unclear whom their theories are for, that is, who the audience for highly systematic ethical theorizing is supposed to be.

Jeroen Hopster explores the ethics of climate change through the lens of evolutionary ethics, arguing convincingly that the adoption of an evolutionary perspective on climate change can both hinder and advance our understanding of what is at stake. It can hinder it by inviting geological or Darwinian relativism, which downplay the gravity of current developments. At the same time, evolutionary ethics can help us understand and perhaps overcome the cognitive biases and moral blind spots that explain widespread moral disengagement with the problem of climate change. Intriguingly, Hopster suggests that one promising way of encouraging more responsible behaviour would be to appeal to the pride that people could derive from successfully fighting climate change.

An original take on the societal relevance of philosophy, especially ethics, is offered by Ibo van de Poel, who argues that in order to enhance its relevance, philosophers must not only ask different questions but also employ different methods. Van de Poel takes issue with the widespread reliance on contrived toy problems, such as the notorious trolley dilemma, on the grounds that real-world problems are often relevantly different from the toy problems that are so meticulously studied by philosophers. If they are to offer socially relevant solutions, van de Poel, taking cues from Dewey, suggests that philosophers should make more use of 'synthetic' methods. These include the proper formulation of philosophical problems (e.g. by considering the context in which they arise), the designing of problems (e.g. by changing a dilemmatic situation in such a way that is ceases to be a dilemma), as well as the experimental testing of philosophical solutions in the real world (by trying out a course of action, observing its consequences, and learning from it).

The above review is inevitably selective, and it should be noted that the volume contains further contributions that have an ethical topic (e.g. Richard Swinburne's chapter on simplicity in metaphysics and ethics and Rozemund Uljée's treatise on responsibility in Heidegger and Derrida) or that are indirectly relevant to ethicists, discussing methodological and meta-philosophical questions. The volume is ambitious in its scope, reflecting the unusually diverse research interests of the festschrift's honouree, but the editors and authors have done a good job at showing how the various themes and threads are related. While some essays discuss only one of the three themes of the volume (progress, method, relevance) and others several at once, they jointly convey a good sense of how the three seemingly disparate topics are connected. On a more critical note, some readers might miss a contribution from political philosophy, a discipline in which many related methodological and metaphilosophical questions are currently being discussed. Still, the volume is highly recommended to both practical and theoretical philosophers, and especially to 
everyone pondering meta-philosophical questions about how philosophy ought to be done, where it is headed, and what its role should be within society. With metaphilosophy on the rise, it is safe to predict that the essays collected in this volume will remain relevant in the years to come.

Funding Open Access funding enabled and organized by Projekt DEAL.

Open Access This article is licensed under a Creative Commons Attribution 4.0 International License, which permits use, sharing, adaptation, distribution and reproduction in any medium or format, as long as you give appropriate credit to the original author(s) and the source, provide a link to the Creative Commons licence, and indicate if changes were made. The images or other third party material in this article are included in the article's Creative Commons licence, unless indicated otherwise in a credit line to the material. If material is not included in the article's Creative Commons licence and your intended use is not permitted by statutory regulation or exceeds the permitted use, you will need to obtain permission directly from the copyright holder. To view a copy of this licence, visit http://creativecommons.org/licenses/by/4.0/.

Publisher's Note Springer Nature remains neutral with regard to jurisdictional claims in published maps and institutional affiliations. 